\title{
El hallazgo Numismático de la Taifa de Sevilla en Aracena (Huelva)
}

Alberto Canto García Dpto. Prehistoria y Arqueologia. Universidad Autónoma de Madrid Eduardo Romero Bomba

Timoteo Rivera Jimenez Omar Romero de la Osa Fernández

Recibido: 5/03/2015

Revisado: 13/04/2015
Aceptado: $14 / 04 / 2015$

Publicado: 30/05/2015

\section{RESUMEN}

En el transcurso de una intervención arqueológica en el castillo de Aracena (Huelva) se encontró un conjunto de siete dinares de los abbadíes de Sevilla, en concreto, de Abu Amr Abbad al-Mutadid. Entre ellos se encuentran algunos ejemplares de rareza notable.

\section{ABstract}

A group of seven dinars of the Abbadids of Seville, particulary, of Abu Amr Abbad al-Mutadid, has been found in the course of an archaelogical intervention in the castle of Aracena (Huelva). Among them are some rare exemplars.
Palabras Clave

Al-Ándalus; Huelva; Aracena; Abbadíes; Monedas; Dinares.
KEYWORDS

Al-Ándalus; Huelva; Aracena; Abbadids; Coins; Dinar.

alberto.canto@uam.es

eduardo.rbomba@alu.uhu.es

timoteo.rivera.ext@juntadeandalucia.es

omar_romero_fdz@hotmail.com 
El hallazgo de siete dinares de la taifa abadí de Sevilla durante la intervención arqueológica ${ }^{1}$ realizada en el castillo de Aracena durante 2012 viene a contribuir, junto al resto de la cultura material que se ha documentado, a la definición de la secuencia de ocupación del lugar, pero también aporta información al conocimiento histórico ya que su cronología coincide con la política de expansión y con-

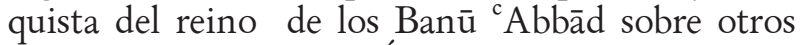
territorios de Gharb al-Ándalus. En el castillo de Aracena se ha evidenciado un poblamiento andalusí, previo a la edificación del conjunto fortificado, que se inicia en los siglos X-XI ya que se han documentado estructuras y cultura material de las etapas califal y taifa aunque la arquitectura doméstica mejor conservada es de los siglos XII-XIII. Las viviendas islámicas formarían parte de la población conquistada por Portugal, a través de la Orden del Hospital, a mediados del s. XIII.

Los inicios del siglo XI fue la etapa de desintegración del califato Omeya de Córdoba y el triunfo de los poderes locales que surgen en todo al-Ándalus como "reinos de taifa" donde se atomizará el poder. Entre los primeros territorios en proclamar su autonomía se encontraba la taifa bakrí de HuelvaSaltes en 402 H/1012 d. C. (García Sanjuán, 2003) y Badajoz en 403 H. /1013 d. C. Al año siguiente Silves sigue su ejemplo y en 407 H. /1016-1017 d.C. es el turno de Faro. Mértola proclama su autonomía en 410 H. /1020 d.C. En Gharb al-Ándalus, los últimos en tomar el poder fueron los cabbādíes de Sevilla y la dinastía yahṣubí de Niebla en 414 H. /1023 d.C. (Viguera, 1994; Picard, 2000; Garcia Sanjuán, 2003).

Desde 1030 las luchas entre los diferentes reinos de taifa tendrán el objetivo de la expansión territorial ya que tras una primera etapa donde proliferan los poderes locales, las dinastías más poderosas van absorber a los reinos más pequeños hacia mediados del siglo XI. De esta manera, los abbadíes de Sevilla se anexionarán los territorios del sur del Gharb al-Ándalus. La cronología de esta expansión no está definida claramente ni en las fuentes ni en la historiografía (Viguera, 1994; Picard, 2000; Tahiri, 2001; Garcia Sanjuán, 2003; Lirola, 2011). Podemos señalar que su inicio se sitúa en el conflicto con el reino de Badajoz con cuyo territorio limitaba en el

1. Agradecemos con estas líneas la colaboración para este estudio del conservador del Museo de Huelva. D. Enrique Martín Rodríguez. ámbito geográfico de Aracena. La zona occidental de Sierra Morena formó parte de una encrucijada de límites administrativos durante las etapas emiral y califal ya que su territorio estaba englobada en las Coras de Beja, Sevilla, Mérida, Niebla y Firrish. En concreto, Aroche estaba integrada en la Kūra de Bāŷa, mientras que la zona oriental (āqālim de al-Munastīr y Qațrašāna) estaba bajo la jurisdicción de la kūra de Išbīliya. Un ejemplo que nos resalta la importancia del hallazgo numismático y su contexto es la cita del geógrafo del s. XI, Abū 'Ubayd al-Bakrī, en su obra Kitāb al-masālik wa-lmamālik, escrita hacia el año 460 H (1067-1068 d. C.), que señala que en tiempos del emir al-Hakam I (206 H./ 822 d. C.) los āqālim de la jurisdicción de Sevilla, entre ellos al-Munastīr, donde se recaudaba la ŷibāya habían conseguido más de 35.000 dinares.

El territorio de Beja (Bâŷa) que era dominado por los aftasíes de Badajoz pasó a manos sevillanas en 420 h/1029 d. C. (Macías, 2005). En 435 H. /1044 d. C., fue conquistada Mértola (Macías, 2005). En el año 443 H. /1051-1052 d. C., los abbadíes se apoderaron de Walba y Šaltîs (Huelva y Saltés) regidas por los Bakríes y de Faro gobernado por los Banû Hârûn. En el año 445 H. /1053 d. C. se apoderaron de Niebla y Gibraleón dirigidas por los Yahsibíes y Silves, administrada por los Banû Muzayn, fue tomada en el año 455 H. /1063 d. C., (Picard, 2000; García Sanjuán, 2003). De esta manera, durante el siglo XI, Gharb al Ándalus, fue repartido entre las taifas de Badajoz y Sevilla, convirtiendo la comarca de Sierra Morena Occidental donde se enclava Aracena en una zona fronteriza, o mejor dicho, intercambiando su papel de límite administrativo por un limes demarcatorio.

El hallazgo numismático se produjo en la zona occidental del castillo, concretamente en el ángulo Oeste del alcázar, donde se dispuso el sondeo 2B. El objetivo de la intervención en el alcázar del castillo de Aracena era documentar la arquitectura militar del recinto pero los trabajos arqueológicos han constatado la existencia de arquitectura doméstica de época andalusí. En concreto se ha evidenciado un poblamiento del periodo norteafricano, previo a la edificación del conjunto fortificado, basado en la presencia de viviendas islámicas con una cronología entre los siglos XII y XIII que formarían parte de la población conquistada por Portugal, a través de la Orden del Hospital, a mediados del s. XIII. Así mismo se ha constatado, mediante el estudio de la secuencia estratigráfica y de la cultura material, 
la existencia de estructuras anteriores que fueran amortizadas por las viviendas del periodo norteafricano y que se fechan en momentos califales-taifas. Las estancias asociadas a viviendas de época islámica se están documentado en la cumbre del cerro, por lo que se puede deducir que se integran en un núcleo poblacional, a lo que se une la presencia de elementos como atarjeas o viales que denotan la existencia de urbanismo, de una planificación a la hora de construir. El urbanismo de esta población se plasma en las características de las viviendas islámicas con su adaptación a la orografía del cerro, disponiéndose de forma escalonada, siguiendo las curvas de nivel y la agrupación de las casas en manzanas. Se desconoce su extensión aunque se ha constatado una amplia dispersión de material islámico en superficie y se documentan estructuras en distintos puntos del cerro. Ello nos permite aseverar que el cerro del castillo de Aracena, donde se erige la iglesia Prioral y las ruinas de la fortaleza, fue el núcleo original del poblamiento de la localidad desde la época califal-taifa.

El sondeo 2B se planteó como una zona de excavación para dilucidar el comportamiento del pobla- miento en el cerro del castillo, así como para aportar información sobre elementos estructurales de la fortaleza medieval. Su ubicación estaba motivada por presentar una mayor potencialidad estratigráfica, lo cual se constató al deparar una secuencia poblacional desde el s. X. Podemos definir dos grandes fases en la etapa de poblamiento islámico: fase califal-taifal y fase norte-africana. Esta última fase es amortizada por la construcción del castillo, así como por las continuadas fases de ocupación bajomedieval de los siglos XIII-XV.

La construcción del castillo conllevo la destrucción de las estructuras de la población andalusí cuyos derrubios fueron empleados para nivelar el terreno. En el sondeo $2 \mathrm{~B}$ se documentó la planta de la vivienda 1. Tanto esta, como las restantes estructuras domésticas documentadas responden a los cánones de las viviendas islámicas. Este modelo de casas, con patio central y una distribución periférica de las habitaciones que están jerarquizadas y diferenciadas en sus funciones, están datadas desde los siglos XII y XIII. Se corresponden con un modelo generalizado con salones rectangulares y cierta especialización

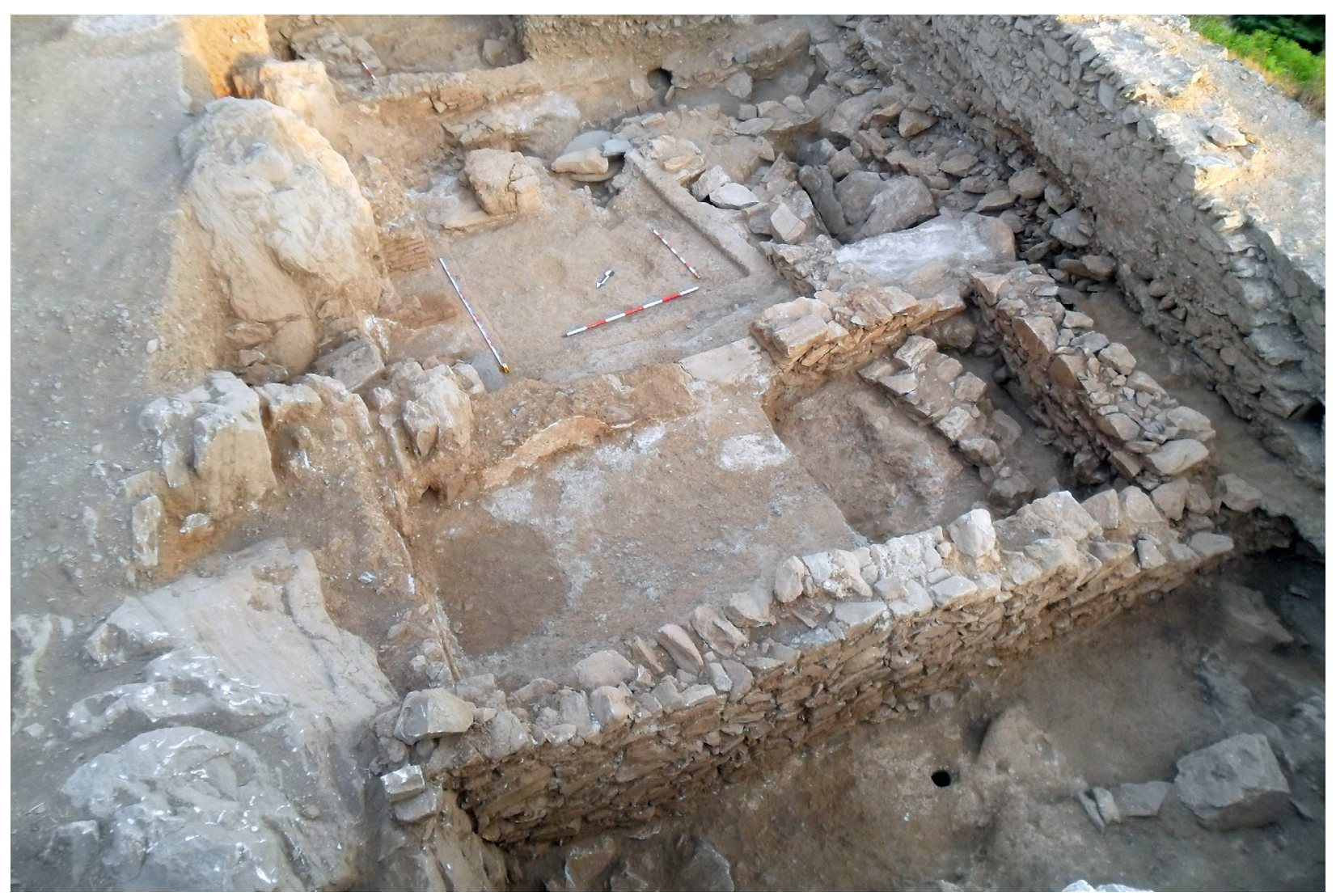

Figura 1: Vista general de la Vivienda 1, de época almohade, donde se observan las estructuras amortizadas de época califal-taifa, así como la estructura 7 
de los espacios. Se integran en la definición de "casas complejas" (Navarro, 1990). La construcción de la vivienda 1 conllevó una remoción del terreno y la amortización de niveles y estructuras de la fase de poblamiento de los siglos X-XI.

En el sondeo 2B se pudo constatar la amortización de una vivienda anterior por la casa del periodo norte-africano (Fig. 1). Se evidencia porque el nivel de uso de la estancia A colmató mediante un relleno el pavimento, a una cota inferior, de otra habitación. Así mismo, los muros de la estancia A se superponen a los muros (18 y 19) que delimitan un espacio doméstico aunque presentan una orientación diferente. Estas evidencias estructurales nos están indicando la existencia de una vivienda anterior a la morada del periodo norte-africano que puede ser encuadrada cronológicamente, en base a la cultura material, en la época califal-taifa (siglos $\mathrm{X}-\mathrm{XI}$ ). Por tanto se puede deducir que se ha producido una importante reforma en esta vivienda. En el interior del espacio se ha documentado restos de un pavimento de arcilla y cal de color albero o glazzie que también se documenta al exterior de la

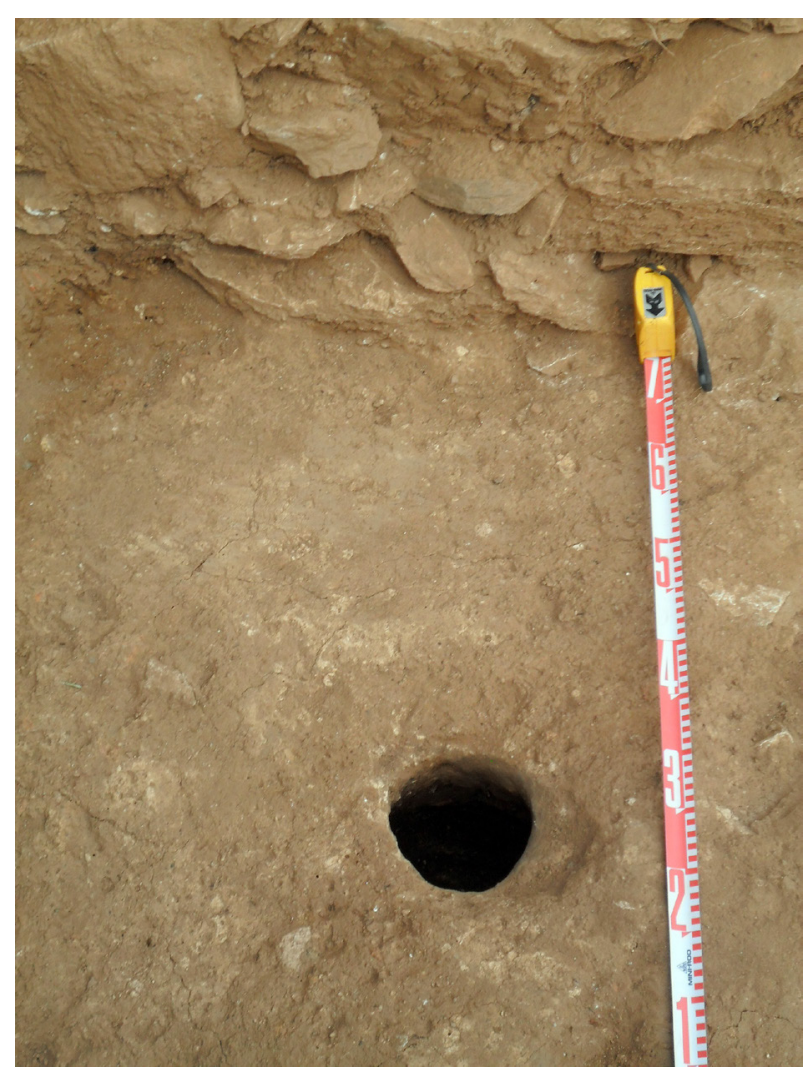

Figura 2: Detalle de la estructura 7 o lugar de ocultamiento original de los dinares, excavado en el subsuelo vivienda y donde fue excavada la estructura 7. Esta estructura, atendiendo a sus características, es el lugar de ocultamiento original de las monedas del conjunto y se integraría en el ámbito doméstico de la vivienda de los siglos X-XI. Es una oquedad conformada en el suelo de forma cilíndrica, con un diámetro de $12 \% 5$ cts. por 26 cts. de profundidad. Sus paredes interiores están alisadas aunque con una conformación irregular. Está excavado en un sustrato de tipo ígneo, con sedimentos de color amarillento, que el MAGMA define como granito anatexico de afinidad chaznockitica (ortogneis). Se encuentra al exterior de la vivienda 1 , datada en los siglos XII-XIII, y en el interior de la esquina occidental que conforman los lienzos murarios del castillo. Esta ubicación es clave para explicar las circunstancias post-deposicionales del hallazgo de los dinares (Fig. 2).

La unidad estratigráfica (UE62) donde se documentó el hallazgo numismático es un nivel de sedimentos de color negruzco, presente tanto al exterior como al interior del muro 1 de la estancia A. Estratigráficamente se situaba al exterior del muro 1 por debajo de un nivel de derrumbe (UE61) de la estructura muraría y cubría a UE63, sustrato de tipo ígneo donde se excavó la estructura 7 , mientras que hacia el interior de la estancia, lo sellaba un suelo de cal, el nivel de uso de la estancia A y el relleno que permitía su nivelación (UE22). Sobre dicho suelo de cal, aparecía a su vez el mismo nivel de derrumbe que hacia el exterior.

La secuencia estratigráfica y el repertorio ergológico, nos hace pensar en un nivel de relleno intencionado, preparatorio para la construcción de la casa 1. Debió ser rápido, de ahí que uno de los dinares apareciese completamente de perfil en la matriz del relleno (Fig. 3). Probablemente, en dicha preparación, se localizase la estructura 7 destruida superficialmente, y se recuperase su contenido, a excepción de las monedas localizadas durante la intervención arqueológica, que quedaron incorporadas en la matriz del relleno. La unidad estratigráfica 62, también se vio alterada durante los trabajos de restauración del castillo que tuvieron lugar entre finales de los años 60 y principios de la década de los 70, y no descartamos que en esos momentos, los operarios que realizaban la excavación para la apertura de la zanja de cimentación de la muralla, hubiese podido encontrar alguna otra moneda.

A esta fase también podemos adscribir la estructura 8 que definimos como una sub-estructura que 


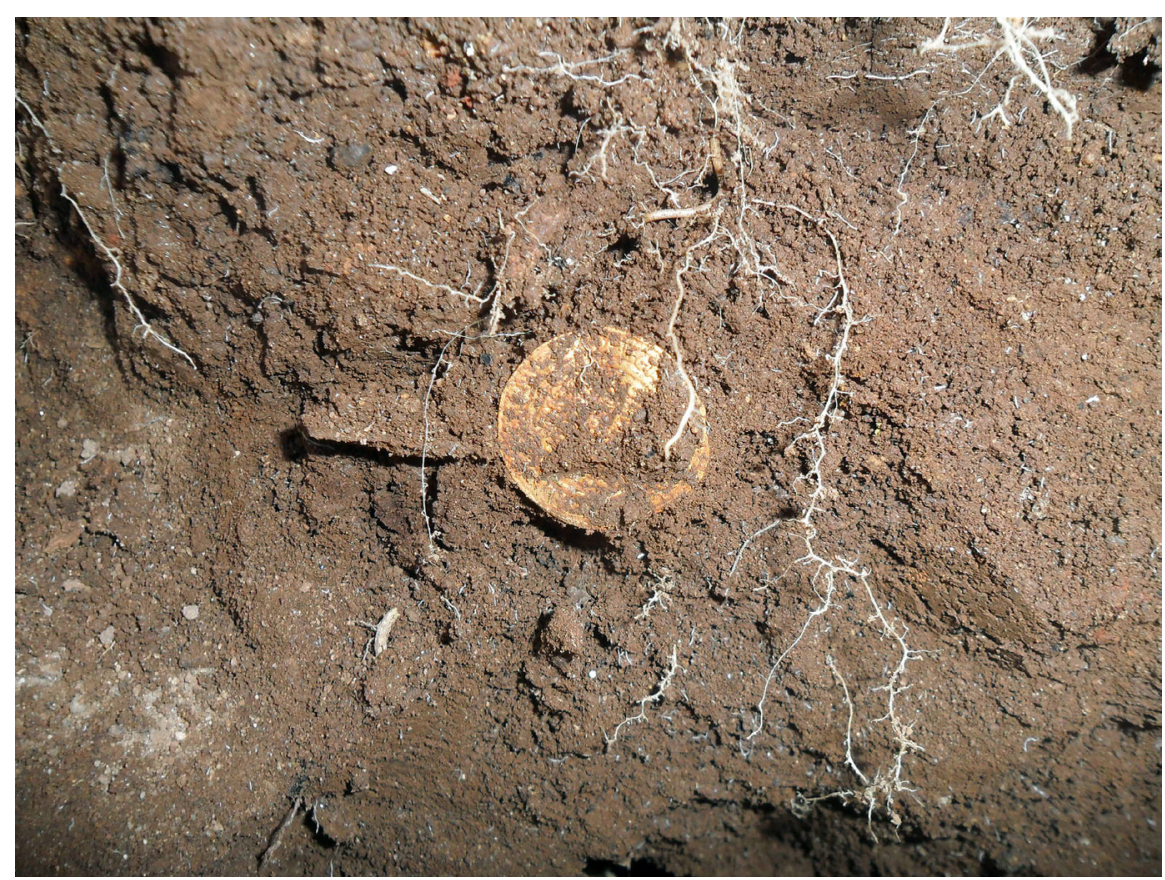

Figura 3: Hallazgo de dinar en un perfil del corte durante el proceso de excavación, con una posición vertical que indican un nivel de relleno intencionado.

se inserta en el espacio interior conformado por los muros 18 y 19, es decir, dentro de la vivienda de época califal-taifa. No por ello, se debe considerar un uso coetáneo al de la casa ya que las relaciones estratigráficas nos indican que el silo fue colmatado para construir esta estancia, por tanto se debe datar en un momento anterior, pero dentro del periodo califal-taifa ya que la cultura material que se ha documentado en su interior fecha en estos momentos, su colmatación. Las características del sustrato geológico permiten su excavación y la conservación de los materiales que se almacenasen frente al sustrato de mármoles que está presente en parte del cerro del castillo. Parece corresponder a un tipo de silo geminado, con una sub-estructura principal, en el centro, y otras dos adyacentes de menor tamaño. Presentan planta pseudo-circular, con un perfil acampanado. El diámetro máximo es de 1,95 metros, mientras que su altura es de 1,18 metros. El relleno interior es uniforme con abundantes restos de tejas, piedras y material cerámico.

La cultura material que permite fechar esta fase está compuesta por jarros y jarritas con decoración pintada en trazos rojos y blanco, candiles de piquera, alcadafes decorados con almagra y ataifores donde sobresale la decoración verde y morado con motivos vegetales (palmetas, hojas) y geométricos (cenefas, franjas paralelas, círculos en el borde) que presentan cubierta melada mayoritariamente. Este material cerámico permite encuadrar esta fase entre los siglos X al XI.

El hallazgo numismático que estudiamos no es el único que se ha producido en el cerro del castillo ya que en la obra, Huelva, de Amador de los Ríos (1983) se describe: "en Aracena fue encontrado un ad-dinar o moneda de oro, probablemente referible al califato de Al-Hakém I, acuñado en España en el año acaso, en el cual la leyenda se haya repartida de la siguiente forma:

\section{Anverso:}

-centro: En el nombre de Alláh El Clemente El Misericordioso

- Orla: fue acuñado este ad-dinar en Al-Ándalus el año dos y doscientos (?)

\section{Reverso:}

- centro: No hay otro dios Que Alláh El único - orla: Mahoma es el legado de Alláh. Envióle con la dirección y ley de la verdad."

Sin embargo esta descripción de Amador de los Ríos plantea más dudas que certezas. La ausencia de dinares acuñados bajo el emirato omeya independiente de al-Ándalus es algo absolutamente constatado en la bibliografía numismática y, por lo tanto, 
nos parece que debe ser rechazada la atribución establecida por Amador de los Ríos sobre esta moneda. Asimismo, la distribución epigráfica y descriptiva de la moneda no se asemeja a nada de lo que se acuña en al-Ándalus bajo los omeyas en la fecha propuesta por Amador. Las únicas monedas de oro que circulan en las fechas del emirato omeya serían los dinares aglabíes, cuyas leyendas y aspecto, tampoco se parecen a la pieza mencionada.

Sin embargo la distribución de leyendas que menciona, haciendo la salvedad del cambio de orden de los campos, parece ajustarse al tipo del dinar de primera época del año 102H. / 720-1 d.C. (Vives 1893, $\mathrm{n}^{\mathrm{o}}$. 14; Miles 1950, no .2 ), tanto en la lectura de los campos centrales cómo en las orlas. Si se acepta esta posibilidad se trataría de un error de lectura del dígito de la centena de 102 por 202 algo extraño pero no imposible. De ser correcta nuestra propuesta se trataría pues de un dinar del momento de la conquista. Por ello y ante la ausencia de una imagen que pudiera aportar más luz al respecto nos inclinamos por descartar de manera absoluta la atribución citada pero dejando la puerta abierta a esta posible atribución coherente con la epigrafía mencionada por Amador.

\section{EL CONJUNTO NUMISMÁTICO}

Como se ha dicho el hallazgo está compuesto por siete dinares de la dinastía de los abbadíes con fechas entre el 441H. / 1049 d.C. y el 453H. / 1061 d.C., por lo tanto acuñadas bajo el reinado de Abu Amr Abbad al-Mutadid.
1.- Dinar Al-Ándalus 441H. / 1049 d.C. (Fig. 4) $2,96 \mathrm{~g} 23 \mathrm{~mm} \quad$ Prieto $397 \mathrm{f}$.

2.- Dinar Al-Ándalus 441 H. / 1049 d.C. (Fig. 5) $3,11 \mathrm{~g} 23 \mathrm{~mm} \quad$ Prieto $397 \mathrm{f}$.

$\begin{array}{cl}\text { 3.- Dinar Al-Ándalus } & 443 \mathrm{H} \text {. / } 1051 \text { d.C. (Fig. 6) } \\ 3,56 \text { g } 23 \mathrm{~mm} & \text { Prieto 397j. }\end{array}$

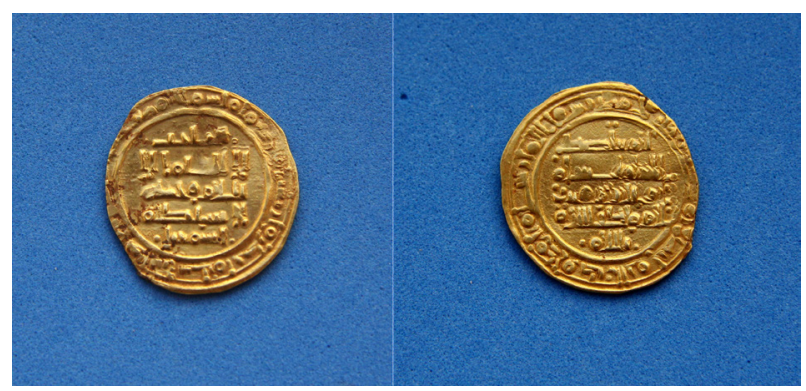

Figura 4: Dinar, Al-Andalus (441H.), Prieto 397f.

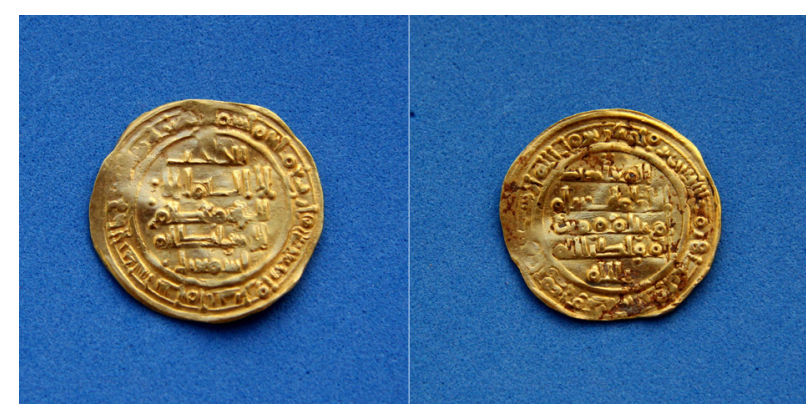

Figura 5: Dinar, Al-Andalus (441H.), Prieto 397f.

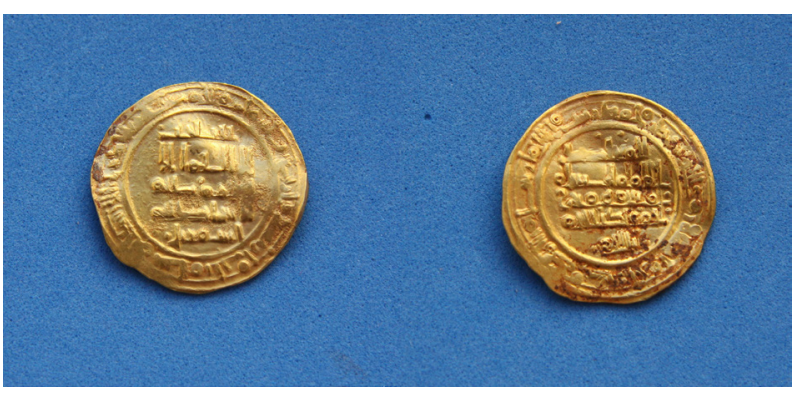

Figura 6: Dinar, Al-Andalus (443H.), Prieto 397j.

Dinar considerado como único por Prieto en su obra y la moneda que cita es la del Instituto Valencia de Don Juan de Madrid; si se compara con este ejemplar parecen proceder del mismo cuño de anverso siendo el de reverso distinto (Fig. 7).

\section{4.- Dinar Al-Ándalus 445 H. / 1053 d.C. (Fig. 8) $2,00 \mathrm{~g} 23 \mathrm{~mm} \quad$ Prieto $397 \mathrm{n}$.
5.- Dinar Al-Andalus 448 H./ 1056 d.C. (Fig. 9) 3,07 g $26 \mathrm{~mm} \quad$ Inédita, similar a Prieto 397q (dirham)

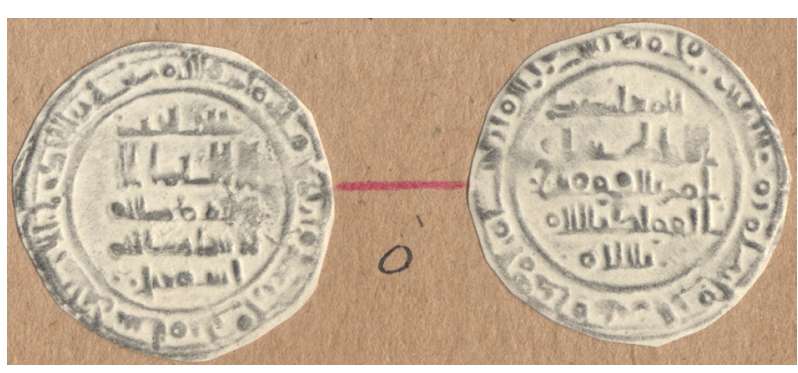

Figura 7: Impronta del dinar de al-Andalus del año $443 \mathrm{H}$., de la colección Oma (Inst. Valencia de Don Juan, Madrid) (Proy. Estudio y clasificación del material gráfico numismático de época andalusí, depositado en el instituto Valencia de Don Juan de Madrid, $\left(\mathrm{n}^{\mathrm{o}}\right.$ ref. 06/0131/2002) dirigido por el Dr. Alberto Canto García. 


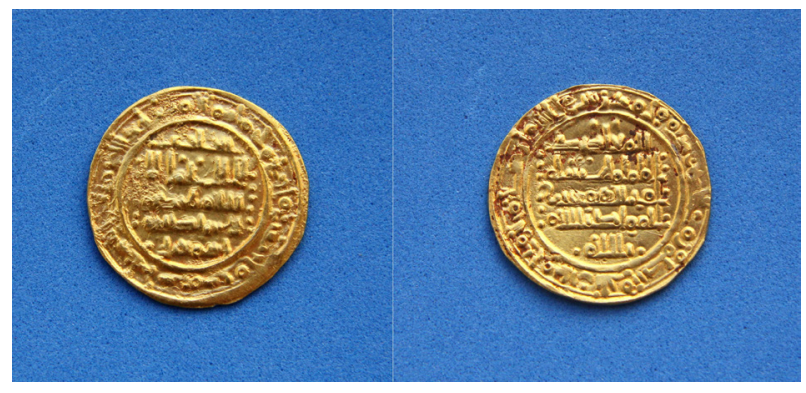

Figura 8: Dinar, Al-Andalus (445 H.), Prieto 397n.

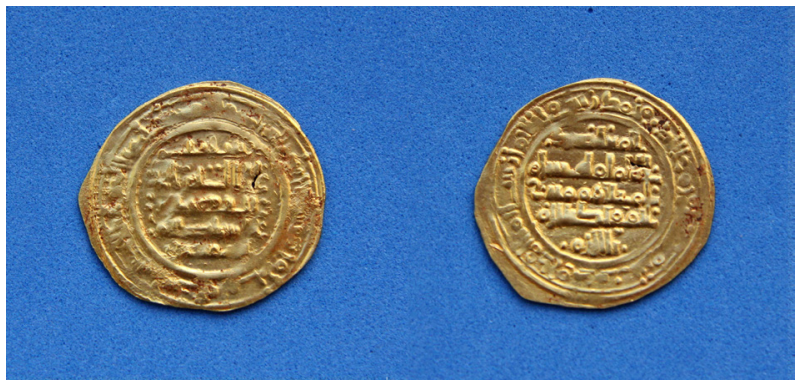

Figura 9: Dinar, Al-Andalus (448 H.), Inédita, smilra a Prieto $397 \mathrm{q}$ (dirham).

La fecha está algo borrosa, dado el estado de conservación de la moneda, pero parece que la lectura del dígito 8 parece clara. Por otra parte, aunque el último dinar de esta serie, recogido por Prieto, es del año $445 \mathrm{H}$. /1053 d.C., existen monedas de plata hasta este año 448H. / 1056 d.C., por lo que no es de extrañar la existencia de emisiones en oro (Prieto 1929, 229).

\section{6.- Dinar Al-Ándalus 451 H. / 1059 d.C. (Fig. 10) $3,14 \mathrm{~g} 23 \mathrm{~mm} \quad$ Prieto Suplemento 152.}

El único ejemplar conocido, hasta la fecha, era el depositado en el Instituto Valencia de Don Juan de Madrid, cuya impronta ha sido publicada (Fig. 11). El tipo era conocido en dírham (Prieto 1926, $\mathrm{n}^{\mathrm{O}}$.

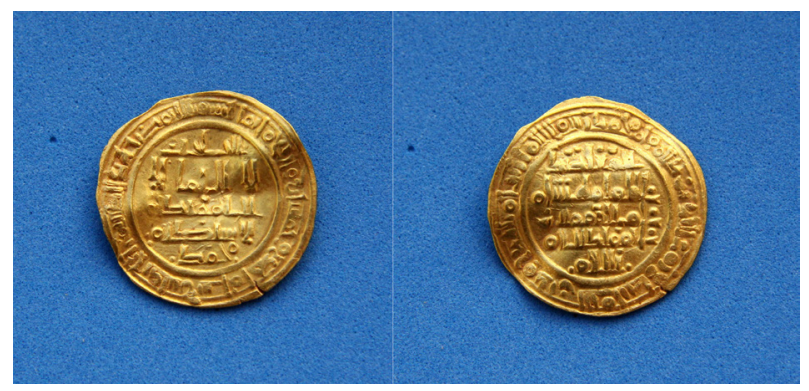

Figura 10. Dinar, Al-Andalus ( 45 H.) Prieto Suplemento 152.

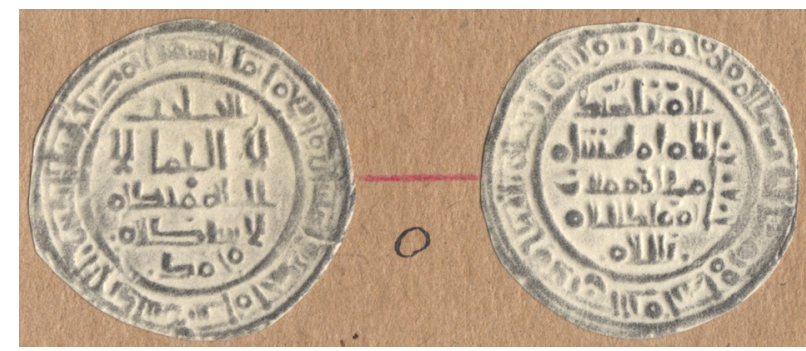

Figura 11: Impronta del dinar de al-Andalus del año 451H., de la colección Oma (Inst. Valencia de Don Juan, Madrid), Proy. Estudio y clasificación del material gráfico numismático de época andalusí, depositado en el instituto Valencia de Don Juan de Madrid $\left(\mathrm{n}^{0}\right.$ ref. 06/0131/2002), dirigido por el Dr. Alberto Canto García.

398b) pero no en oro hasta la citada publicación. Dado que en el año anterior, el 450 H. /1058 d.C., había empezado a acuñarse la serie en la que $\mathrm{Mu}-$ hammad sucede a Ismail como haŷib (Prieto 398 a, c, e, g, i y j), la existencia de dinares de este año parecía lógica como este hallazgo corrobora.

Sí se compara la foto de este ejemplar de Aracena con la impronta de moneda del instituto Valencia de Don Juan se puede asumir que se trata de ejemplares del mismo cuño, tanto en el anverso como en el reverso, lo que corrobora en la rareza de esta emisión.

\section{7.- Dinar Al-Ándalus 456 H. / 1063 d.C.(Fig. 12) $3,36 \mathrm{~g} 23 \mathrm{~mm} \quad$ Prieto $398 \mathrm{j}$.}

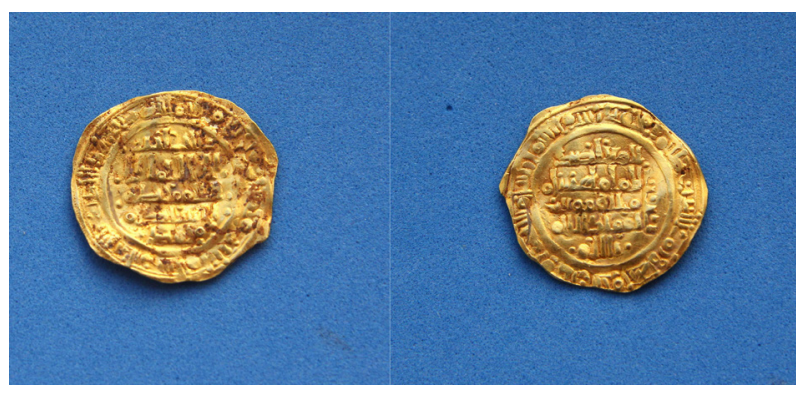

Figura 12: Dinar, al-Andalus (456H.), Prieto 398j.

Como conclusión se trata de un conjunto de dinares muy interesante, tanto por la información de carácter arqueológico que proporciona la excavación, como por la rareza de los ejemplares que lo componen. En un caso por la aportación de una posible fecha desconocida y otros dos ejemplares que, hasta este hallazgo eran tenidos como únicos o 
rarísimos. La rareza de las emisiones como sugiere la identificación de cuños en dos de los ejemplares presentados proporcionan información complementaria sobre las capacidades y el potencial económico de la taifa de Sevilla.

Resulta llamativo que esta taifa, de enorme importancia económica para al-Ándalus en el siglo XI, no haya sido objeto de una profunda revisión en lo que atañe a sus producciones monetarias puesto que seguimos basándonos en tres obras básicas (Codera 1875, Vives 1893, Prieto 1929 y 2003). Es de esperar que futuros trabajos más exhaustivos en esta línea ayuden a precisar con más exactitud la secuencia de las acuñaciones en oro de la dinastía abbadí, una de las más importantes de las taifas del siglo XI en al-Ándalus.

\section{Bibliografía}

Amador De Los Ríos, R. (1983), Huelva, Ed. Facsímil, Barcelona.

Campos, J., Gómez, F. y Pérez, J. A. (1999), “Actuación arqueológica de urgencia en el cerro del Castillo de Aracena (Huelva), Anuario Arqueológico de Andalucía/ 1994, III, 192-194.

Codera y Zaidín, F. (1875), "Estudio histórico. Crítico sobre las monedas de los Abbadíes de Sevilla”, Museo Español de Antigüedades, 6, Madrid.

García Sanjuán, A. (2003), Evolución histórica y poblamiento del territorio onubense durante la época andalusí (Siglos VIII-XIII), Universidad de Huelva, Huelva.

Lirola, P. (2011), Al-Muctamid y los Abadies. El esplendor del reino de Sevilla (s. XI), Fundación Ibn Tufayl-Ayuntamiento de Sevilla, Sevilla.

Macías, S. (2015), La Kūra de Beja et le territoire de Mértola entre l'antiquité tardive et la reconquête chrétienne, Tesis Doctoral, Université Lumière- Lyon II.

Navarro Palazón, J. (1990), "La casa andalusí en Siyâsa: ensayo de una clasificación tipológica”, La casa hispano-musulmana. Aportaciones de la arqueología, Patronato de la Alhambra, Granada, 177-198.

Pérez, J. A., Campos, J. y Gómez, F. (1998), “Aproximación arqueológica al castillo de Aracena y a las fortificaciones de la Banda Gallega”, Huelva en la Edad Media 20 años después, Universidad de Huelva, Huelva, 281-303.

Pérez, J. A., Rivera, T., y Romero, E. (2005), “La fortificación del territorio en época islámica”. La Banda Gallega (J.A. Pérez y J.L. Carriazo, Eds.), Universidad de Huelva, Huelva, 17-66

Picard, C. (2000), Le Portugal musulman (VIIIeXIIIe siècle). L'Occident d'al-Andalus sous domination islamique, Maisonneuve et Larose, Paris.

Prieto y Vives, A.. (1926), Los Reyes de Taifas, Madrid.

Prieto y Vives, A. (2003), Los Reyes de Taifas, ed. Facsímil y Suplemento por T. Ibrahim y A. Canto, Madrid.

Romero, E., Rivera, T. y Pérez, J. A. (2010), "La villa fortificada de Aracena: fases de ocupación”. $V$ Congreso Internacional sobre fortificaciones: Fortificación y ciudad, Alcalá de Guadaira, 51-55.

Romero, E., Rivera, T. y Pérez, J. A. (2013), “Cerámicas islámicas de Almonaster la Real y Aracena (Huelva)", Arqueologia Medieval, 12, 129-144

Tahiri, A. (2001), Agricultura y poblamiento rural en Sevilla durante la época ${ }^{c} A b a ̂ d \hat{\imath}$, Ayuntamiento de Sevilla, Sevilla.

Viguera Molins, Ma․ J. -Coord.- (1994), Los reinos de taifas: Al Ándalus en el siglo XI, Historia de España de Ramón Menéndez Pidal, VIII, Espasa Calpe, Madrid.

Vives Escudero, A. (1893), Monedas de las dinastías arábigo-españolas, Madrid. 